Jens M. Mertens

\title{
Privatrechtsschutz und vertikale Integration im internationalen Handel
}

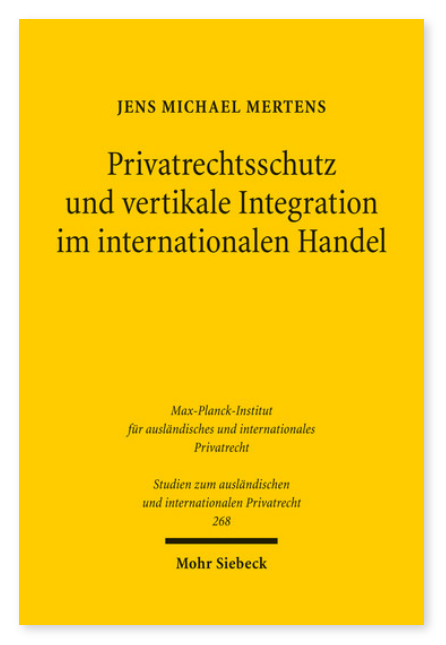

2011. XIII, 268 Seiten. StudIPR 268

ISBN 978-3-16-151770-9

DOI 10.1628/978-3-16-151770-9

eBook PDF 69,00€

ISBN 978-3-16-150959-9

fadengeheftete Broschur $69,00 €$
Staatlicher Privatrechtsschutz spielt im internationalen Handel eine nur untergeordnete Rolle. Um grenzüberschreitende Transaktionen abzusichern, vertrauen Kaufleute meist auf private Governance-Mechanismen. Der Arbeit liegt die These zugrunde, dass diese Substitution des Privatrechts den Prinzipien einer wettbewerblichen Wirtschaftsordnung zuwiderläuft. Denn gleich ob in Form von bilateralen Vertragsbeziehungen, Handelsnetzwerken oder Intrafirmenhandel in transnationalen Unternehmen können private Ordnungen Erwartungsstabilität nur durch persönliche Abhängigkeiten und Hierarchien herstellen - also durch vertikale Integration. Jens Michael Mertens kritisiert, dass dieser Zusammenhang zwischen vertikal konzentrierten Marktstrukturen und den Defiziten des staatlichen Privatrechts auf globaler Ebene in der vom »More Economic Approach« geprägten Wettbewerbspolitik keine Beachtung findet.

Jens M. Mertens Geboren 1982; 2002-07 Studium der Rechtswissenschaften in Münster und Lyon; ab 2008 Wissenschaftlicher Mitarbeiter am DFG Sonderforschungsbereich »Staatlichkeit im Wandel« an der Universität Bremen; seit 2010 Referendar am Hanseatischen Oberlandesgericht in Hamburg.

Jetzt bestellen:

https://mohrsiebeck.com/buch/privatrechtsschutz-und-vertikale-integration-im-internationalen-handel-9783161517709?

no_cache=1

order@mohrsiebeck.com

Telefon: +49 (0)7071-923-17

Telefax: $+49(0) 7071-51104$ 